\title{
FEATURE
}

\section{Determining Use of an Academic Library Reference Collection Report of a Study}

\section{Jeannie Colson}

Jeannie Colson is Distance Education/ Reference Librarian, Lee College, Baytown, Texas. Submitted for review May 5, 2006; accepted for publication July 12, 2006.
Reference \& User Services Quarterly, vol. 47, no. 2, pp. 168-175 (c) 2007 American Library Association. All rights reserved.

Permission granted to reproduce for nonprofit, educational use.
Studies indicate that a lean reference collection is the ideal, but how does a librarian determine what to pare? A small academic library did a five-year reshelving study to guide in collection management. Dots were applied to books as they were reshelved, with different colors for each year. Data indicate that, while many items were heavily used, many others were not used at all in five years. As a result of the study, reference staff are reconsidering the nature of the reference collection, beginning to develop a collection management policy, and determining the disposition of the good, but unused, items.

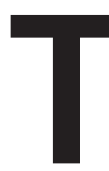

he library that does a use study is attempting to know which items it currently holds will be used next year, and we know from Fussler and Simon's study that "the single best predictor of future use of a book" is past use. ${ }^{1}$ If the reference staff at Columbia International University (CIU) could learn which books are used, we could then create a lean, efficient reference collection by weeding unused books and utilizing the data to select new acquisitions by established use patterns. This study is an investigation into the use of a reference collection at a small academic library focused on what has been used, with an eye to weeding the unused collection of items.

The method used was suggested by Eugene Engeldinger's challenge to make known use the primary criterion for weeding reference collections in his report of a use study done at the McIntyre Library, University of Wisconsin, Eau Claire (UWEC). ${ }^{2}$ The Engeldinger study involved placing one adhesive dot inside the back cover of a reference book each time it was reshelved, up to five times. At the end of five years, the dots were counted, providing the reference staff with quantitative information to supplement instinct as they made weeding decisions. The Eau Claire study was one that the reference staff at CIU's G. Allen Fleece Library could easily replicate.

\section{LITERATURE REVIEW}

According to Robert Broadus, use studies are differentiated from usage studies by the study's object. Use studies focus on the materials and how they are used. Usage studies focus on the patrons and how they use the materials. ${ }^{3}$ Use studies, of course, do not-or should not-exist in a vacuum. The professional literature indicates that the most common reason librarians performed use studies was to support collection 
management decisions. Use studies rightly inform these activities, but they also provide quantitative information to guide the deselecting, pruning, and weeding process. Therefore, literature supporting this research centers on use studies and weeding as each intersects the print reference collection.

Broadus examined conclusions of the library use studies he considered most consequential. ${ }^{4}$ He offered an annotated list of five generalizations that might be drawn from these studies. Even though the Broadus article does not address reference collection use, two of his generalizations are relevant to this study. Broadus's first generalization suggested that a substantial percentage of many libraries' holdings receive no recorded use. The second relevant generalization states that current use is a predictor of future use; that is, items recently used are more likely to be used in the near and distant future.

In 1981, librarians at the San Luis Obispo campus at California Polytechnic State University conducted a title-by-title review of their reference collection. ${ }^{5}$ The review had nine objectives, which included providing an inventory and serving "as a means of purging the reference collection of seldom-used or obsolete books. ..." The results of this study were, perhaps, more dramatic than most librarians would prefer: ". . . the reference collection was reducible from 16,000 titles and 25,000 volumes to a manageable size of 5,540 titles and 14,331 volumes. Furthermore, librarians became more familiar with the scope and depth of the entire collection, as well as in their own subject areas, and with the location of missing items." ${ }^{\prime \prime}$

In 1982, Engeldinger surveyed 377 academic reference librarians about various aspects of their libraries' practices relating to weeding the reference collection. ${ }^{8}$ He found that frequency of material use was a factor for 54 percent of the librarians responding. He also sought to elicit information on how frequency of use was determined. Responses were few, but virtually all who did reply offered only subjective means to assess use.
Biggs and Biggs surveyed 471 reference heads in academic libraries regarding collection development. ${ }^{9}$ Reference collection size was a focus "especially because our perception-which turned out to be confirmed by our findings regarding numbers and frequency of use of reference volumes-that reference collections tend to be too large for thorough exploitation by librarians in the service of information delivery." ${ }^{10}$

Librarians at Iowa State University's Parks Library considered the types of reference materials most necessary to meet patron information needs, as well as reference staffing and training needed. ${ }^{11}$ For four weeks, the librarians tallied usage of reference books, differentiating between usage by reference staff and library patrons. Results were further distinguished by Library of Congress (LC) call number ranges. Usage was defined as "referral to, or reshelving of, a particular reference item," despite the authors' awareness that this method overlooked those items reshelved by the patron and undercounted those used by more than one patron but reshelved by library staff only once. The study informed the library staff about usage of books within each subject (LC classification), which, in turn, informed them regarding potential collection weaknesses.

Truett interviewed fourteen reference librarians to study weeding and evaluation practices. ${ }^{12}$ The main considerations given for weeding were age and use, but no one reported doing formal use studies. Her fourth conclusion is relevant to our purposes:

Virtually all reference librarians respect the importance of weeding; though lacking written guidelines, they often weed their collections continuously and can list a large number of unwritten weeding criteria. However, more formal use studies of reference sources could provide a more objective basis for weeding. Better inventory control procedures are also in order, especially given the lack of precise figures for collection growth or size. ${ }^{13}$
At the UWEC library, the reference staff undertook an empirical study, noting the number of uses each individual volume received..$^{14}$ An item was considered used if it was reshelved by library staff. Student workers affixed as many as five dots inside the back cover of each volume returned to the shelves. After five years, the researchers collected and tabulated the data. The dots revealed that an astonishing 35 percent of the reference collection received no use in five years. If an acceptable use rate is once in five years, then the researchers "could eliminate about onethird of the titles." ${ }^{\prime 5}$ If two uses in five years were the minimum, reference staff could withdraw 51 percent of the collection without notice by the patrons. Engeldinger did not indicate how the data were used for weeding, though he emphasized a much stronger understanding of reference book use is gained by researchers undertaking the study.

Biggs' investigation of the pros and cons of various methods of researching reference book use provides a helpful outline of use study methods librarians have utilized in reference collections. ${ }^{16}$ Her explication of the positive and negative aspects of the reshelving technique reinforced and clarified the comments by Arrigona and Matthews (1988) and Engeldinger (1990). As with most of the authors considered for this study, Biggs bemoaned the lack of, and emphasized the need for, use studies in library reference collections. Similarly, she reported the need in the context of weeding.

One aspect of a study conducted at the William S. Carlson Library, University of Toledo, Ohio, was a use count in which each item replaced had a dot affixed to it. ${ }^{17}$ This article reports on the first year of the study and only provides statistics for the ready reference collection, not for the entire reference collection.

These writings provide the professional and historical context for the research reported in this study. In brief, use studies are easier and more common in circulating collections than in reference collections. All but one of the use studies of reference collections 


\section{FEATURE}

reported in recent years were limited either in time or in scope; that is, reporting use of only a portion of the reference collection.

\section{SETTING}

The G. Allen Fleece Library (GAF) serves CIU's higher education component, which offers bachelor's, master's and doctoral degrees. At its heart, CIU is a bible college and seminary, but not all degrees are in bible-related studies. For example, CIU offers degrees in such fields as intercultural studies, missions, pastoral ministries, and youth ministries as well as Christian education, education, communications, music, psychology, counseling, and teaching English as a foreign language. CIU is accredited by the Southern Association of Colleges and Schools; the Bible College division is an accredited member of the Association for Biblical Higher Education, and the Seminary is accredited by the Association of Theological Schools.

GAF's reference section contains approximately 5,900 noncirculating volumes. In 1999, at the beginning of this study, the reference staff included one full-time librarian, a part-time worker, and a student worker who reshelved reference books daily and recorded the number reshelved. The student worker was the key person for the five years we were to collect data, the one on whom the bulk of the responsibility for the success of the study, fondly dubbed "the dotting project," rested. During the course of the study, the library augmented the reference staff by making the assistant full time and adding two student workers to staff the reference desk. While GAF has a Web-based OPAC, budgetary constraints have prevented adopting an integrated library system (ILS), a lack that certainly made the process more time consuming than it otherwise might have been.

\section{METHODOLOGY}

Reshelving happened only once each day, while the library was closed. Beginning in the fall 1999 semester, a student worker affixed a colored adhesive dot inside the back cover of each reference book to be reshelved, as many as ten dots per book, per year. Each academic year had a distinct dot color to make it possible to identify use per year as well as overall. We anticipated that this system would not add much time to the reshelver's job; in fact, it did. We found that adding a small dot on the spine of books with a full complement of ten for the current year substantially reduced the efforts of the student worker. This did necessitate removing the spine dot each year, a minor chore in view of the greatly relieved daily drudgery of the student worker.

In the third year of the study, reference student workers used the reference shelf list in combination with the OPAC to create an electronic version of the shelf list. Over the next year, we reformatted these data and imported them into a spreadsheet workbook, with each sheet representing one shelving unit, and exported the workbook into a personal digital assistant (PDA). Next, we inventoried the reference collection by comparing the contents of the worksheet with the actual contents of the shelves. A wide range of discrepancies was identified (previously weeded volumes were still in the shelf list, volumes that should have been in reference were wrongly labeled for circulating stacks, shelf list cards for items that had been reclassified had not been updated, catalog records did not agree with the shelf list) and brought to the attention of technical services staff for correction.

At the end of the fifth academic year, three student workers began the process of counting dots. The students received print and oral instructions detailing every step expected, with a strong emphasis on strict attention to detail. The first student was to count dots and state the year and the number for the year. The second entered the data in the PDA, and then repeated back the information to the first student. The researcher admonished the students to read the numbers they reported, not simply repeat what they had heard or thought they had writ- ten. The third worker had the task of removing all but one dot per year from the books. The year and the number of dots for that year were written on the remaining dot.

We limited uploading of information to the reference librarian or the reference associate. Daily, they exported data from the PDA to the library's shared network drive. From there, the reference librarian copied it to her PC and to a $C D$, which went home with her. As the summer of our discontent continued, reference staff agreed that with the learning curve, the problems with writing using the PDA, the screen size, memory, and speed, and the facility that most students now have with typing, the project would have been simpler using laptops instead. It was an interesting experiment, but not one to replicate if a laptop is available.

\section{FINDINGS}

CIU opted to affix as many as ten dots per year, so the maximum a book might receive over five years was fifty. In so doing, we tracked use over time and more accurately assessed each book's usefulness. Over the course of the study, we arbitrarily decided that books with twenty-one to fifty dots could be considered "heavily used," those with six to twenty dots were "moderately used," and items with one to five dots were "lightly used." We found that 12 percent of the reference collection was heavily used, 17 percent was moderately used, and 36 percent was lightly used. While these data seemed positive, affirming the perceived-and actual-value of the reference collection to the GAF library patrons, there is one more number that must be considered: zero.

Fully 35 percent of the books surveyed in this study received no dots at all. Even in the most heavily used area-the BS classification, where the average number of dots per book exceeded twenty-two-fully 5 percent of the books on the shelves had no dots. While such a high number of zeroes was surprising, perhaps it should not have been. If the academic refer- 
ence librarians who participated in the 1985 survey by Biggs and Biggs are representative, lack of use should have been predicted. Biggs and Biggs asked respondents what percentage of their collections they believed were used in four defined time periods and categorized responses based on institution classification. Responses were similar across the classifications: use increases over time, but even over five years, only 62 to 70 percent of the reference collections were estimated to be used. ${ }^{18}$ Empirical evidence seems to back up the intuition of the surveyed librarians, at least in their long-term predictions. Engeldinger's report of the dotting project at UWEC's library noted that 65.2 percent of the reference collection had been dotted at the end of five years. ${ }^{19}$ The Carlson Library at University of Toledo began a dotting project; Sendi's findings-limited to only ready reference-indicated that after the first year, only 57 percent of materials had been used. ${ }^{20}$ Fishman and DelBaglivo, whose study excluded ready reference, reported a one-year reference collection use rate of 65.5 percent in the Health Science Library at University of Maryland. ${ }^{21}$ At GAF, we found that 64.7 percent books were dotted after five years. As with Engeldinger, CIU researchers found that more than 50 percent of the books in the reference collection were used fewer than twice in the five-year period of the study. ${ }^{22}$ Table 1 compares the estimates provided by the Biggs and Biggs survey with these studies.

In addition to simply measuring reference book use, the data were analyzed according to Library of Congress (LC) classification. In some ways, this aspect of the study revealed that reference staff instincts are accurate. As we could have predicted before the study started, books in the BR, BS (Christianity and the Bible) LCC ranges, as well as in the PA (Greek language and litera- ture) and PN (literature) areas, received heavy use as defined above. At an institution in which biblical studies are preeminent, and in which the majority of students are undergraduates, these findings were by no means surprising. The high numbers in the Bs (and low ones in the Ts, for that matter) are misleading without the context provided by comparing the use by LC classification with the total population by LC classification. For example, the lowest non-zero number of uses occurred in the T classification (technology), where six books sported a meager eight dots. However, as the Ts hold only eighteen volumes, 33.3 percent of the books were used. While 33.3 percent does not represent enviable use statistics, it is not nearly as indicative of lack of use as the raw numbers would seem to indicate. Instead of focusing on depth-that is, the number of dots on a given bookwe focused on breadth-that is, the percentage of books within a call number range that received any use. Eleven of the eighteen call number ranges in which the GAF reference collection holds books revealed 67 to 89 percent use. The remaining seven had 31 to 55 percent. We interpreted this to indicate that the librarians who made collection development decisions for the reference collection had effectively provided useful resources in all subject areas. In a context with a chronically inadequate budget, it was gratifying to learn that all areas of the collection were receiving use. Figure 1 shows numbers of books used versus those held by LC classification. Figure 2 provides the same data in terms of a percent.

\section{DISCUSSION}

\section{Use of Print Reference Materials}

The reader might conclude that, based on the discussion above on zeroes, CIU reference collection use declined during the dotting project. On the contrary, during the five years in which the project was taking place, reshelving statistics indicate that use of print reference books increased by 40.4 percent. Consider the following factors that might have influenced this increase in use:

- increase in course-required use of reference resources;

- increase in library instructional sessions introducing and emphasizing reference resources; and

- increased reference librarianinitiated outreach to faculty yielding a concurrent increase in collegiality among the library staff and the teaching faculty.

\section{Electronic Resources}

What influences did access to electronic resources have on the use of the print reference collection? The answer is simple to state definitively: none at all. The only reference tools that CIU subscribed to electronically were World Almanac, through FirstSearch, and Oxford Reference Online. Neither of these is substantive enough to have affected the dotting-or reshelvingstatistics in any relevant way.
Table 1. Librarian Opinion Compared with Use Study Data

\section{Opinion}

Biggs and Biggs

Responses to "What percentage of the reference collection would you estimate is used for reference purposes by librarians or patrons in a..."

\section{Period}

Five years

One year

Six months

One month
$\%$

62.0 to 70.0

43.5 to 49.0

30.0 to 33.0

18.0 to 23.0
Empirical Evidence

$\begin{array}{cccc}\text { Engeldinger } & \text { Sendi } & \begin{array}{c}\text { Fishman and } \\ \text { DelBaglivo }\end{array} & \begin{array}{c}\text { Colson } \\ \%\end{array} \\ \% & \% & \% \\ 65.2 & & & 64.7 \\ & 57.0 & 65.50 & 32.0\end{array}$




\section{FEATURE}

\section{Philosophy}

Library literature repeatedly affirms an almost constitutional aversion among librarians to weeding. Reasons postulated for this aversion include the nature of the librarian (fear of being considered a censor, fear of criticism from the outside), the practice of weeding itself (it is dusty, time-consuming, and frustrating), and even politics. ${ }^{23}$ Data that clearly identify large segments of reference collections receiving little or no use arguably should cause librarians to reflect on the function and focus of these segregated collections.

One can fairly well hear Christopher Nolan screaming as he reports the Biggs and Biggs survey's estimate that in one year, nearly one- third of academic reference collections are unused.

What, then, are these materials doing in reference? Surely items used fewer than once per year do not need to occupy space in a collection selected precisely to provide quick, convenient access. The reference stacks themselves are a file, an organized set of volumes that lead to facts of citations. Cluttering this file with rarely or never used sources merely dilutes the effectiveness of the remaining useful sources. ${ }^{24}$

His question is the one that this study forced the CIU researchers to grapple with. What makes a book a

Figure 1. Book Use Compared with Book Count by LCC

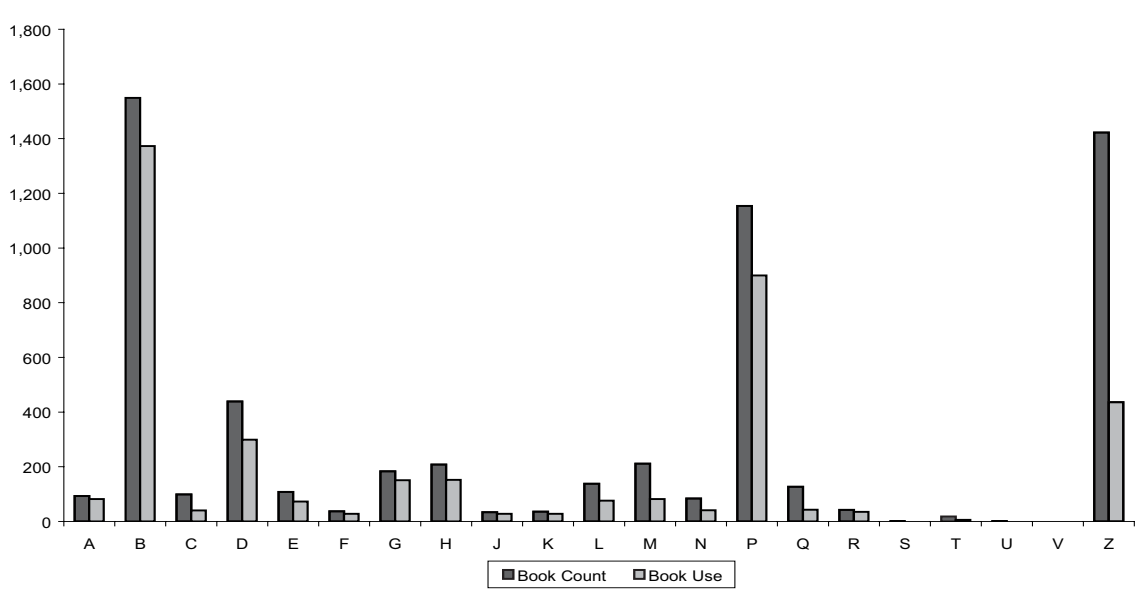

Figure 2. Book Use Compared with Book Count by LC Class

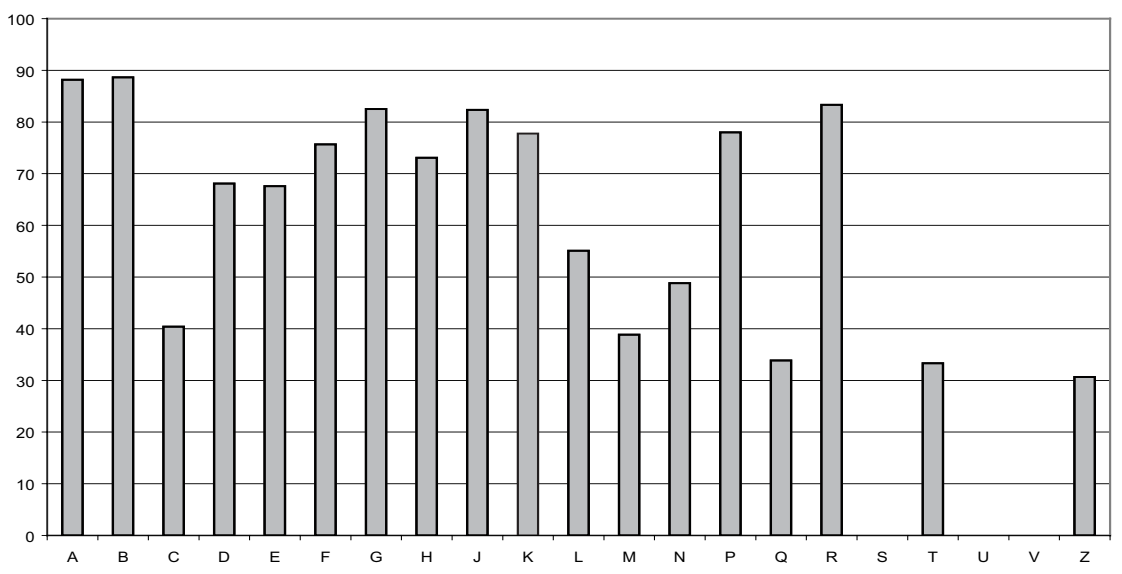

reference book? What is the intended function of a reference collection? How does the academic reference librarian determine that a given book belongs in reference? Nolan describes the typical reference book formats as "pointers" (books that index or "point to" the circulating collection) and "fact books." ${ }^{25}$ He speaks of the reference collection being authoritative, current, and providing unique coverage. Some institutions' reference collections exist to provide equitable access to heavily used items. Many reference librarians include items because "this kind of book belongs in reference, regardless of whether or how much it will be used." The CIU reference collection has been roughly maintained according to both of these standards. But, typically (using the literature as an indicator), the GAF's reference section lacked a defined mission and collection management policy to guide selection and deselection. Addressing these lacks is the first charge of the reference staff. Before weeding, before deciding whether to discard or move individual books to the circulating collection, a mission and policy must be developed. Once developed, it is hoped that the more difficult part of the job-decision-making-will have been strongly aided, and the more tedious parts can be followed with greater confidence than otherwise.

\section{Some Questions to Mull Over When Preparing Policies}

Nolan's quote raises two questions. Does "unused" necessarily equal "useless?" Does "used" imply "good," "authoritative," "best?"

Should use be the sole criterion for weeding? If, as Fussler demonstrates, the greatest predictor of future use is past use, should the librarian limit selection choices to areas where use is already heavy? Should unused or lesser used areas be weeded and no books added? How should new areas of knowledge be treated?

How responsible are the professional bibliographers for ensuring a balanced collection? Should they ever select items for subject areas because 
it is "right" rather than because it will be used?

Whereas weeding is one way to handle unused books, are there other viable options? Promotions? Displays? Guiding students to these resources? Creating assignment bibliographies that include lesser-known items? How much energy should academic librarians expend trying to sell the reference collection to our users?

What about the $\mathrm{Z}$ collection? While it was a surprising revelation that 24 percent of the entire reference collection-the Zs-received only 2 percent of the total use, similar results have been reported by others. In Truett's investigation of weeding policies and practices, she heard from "a couple of librarians" who mentioned the Z collection-particularly subject bibliographies-in their responses. One of the respondents' practice was to put general bibliographies in reference, but to place subject bibliographies in the circulating collection, classified by its primary subject rather than Z. "Besides limiting collection size, it was felt this facilitates browsing by the general public, who are more likely to find a bibliography shelved with its subject." ${ }^{\text {26 }}$

\section{Serendipity}

The reference staff learned much that was unexpected during the course of this study.

The dotting process was very helpful when determining the disposition of gift books. The process for evaluating gift books always has included learning whether duplicate—or alternative editions-of the books are already held in the library. Due to limited space, reference staff avoided adding duplicate copies unless the books were heavily used. Until the dotting project was instituted, GAF had no way to determine objectively how much the existing books were used, and, therefore, the suitability of incorporating additional copies. Now, the bibliographer added to her procedure the practice of counting dots. This one added step tipped the scale toward more objective decision-making and was heartily em- braced by the librarian responsible for gift books.

Until the preparatory work was done, the reference staff had only an estimate-albeit a fairly accurate one-of the number of reference collection books. Once the data were in the spreadsheet, the initial inventory completed, and corrections made to the spreadsheet, we had an exact number. The spreadsheet is being maintained, so the data are accurate and current. We developed methods to track acquisitions and withdrawn reference books separate from the records for the library as a whole, and identified and addressed years-old catalog errors.

The results of the study provided the means to evaluate the reference collection-as a collection and in relation to degrees provided by CIU. We have identified quantitatively which academic majors were well-supported, and where the reference collection was disproportionately distributed.

The $Z$ collection became a surprise source of concern. As mentioned above, 24 percent of the books in the reference collection was in the $\mathrm{Zs}$, an area that received only 2 percent of use.

We learned-almost too late-that it can be dangerous hiring intelligent student workers to do tedious, mindnumbing work. The students who were tasked with counting the dots and entering them in the PDA were excellent reference desk staff and good problem-solvers. Unfortunately, they sought shortcuts to the data collection process. One such shortcut involved entering zeroes in all the cells of the spreadsheet and replacing them as they encountered books with recorded use. Unfortunately, this failed to take into account items that were not on the shelves for whatever reason, and there were a substantial number of these. Between each change in classification, a row had been inserted in the spreadsheet. Here, too, the workers inserted zeroes. While the final number of zeroes was surprisingly high, it was far below what was first revealed when accessing the numbers entered by the creative, problem-solving student workers. As a corollary to this, we learned the maxim "Zero is a number, not a null value."

\section{Caveats}

We are aware of at least three ways in which the data are flawed.

The GAF reference staff did not track acquisitions and deacquisitions as the project continued. For this reason, the statistics for each year reflect the same number of books, an apparent fact, but one that is most assuredly not true. When superseded editions were replaced, the dots were irregularly transferred to the new editions. Books that were weeded but not replaced were simply not accounted for in the system.

We collected data at the volumelevel, not at the title-level. Addressing individual volumes allowed the student workers' efforts to be as simple and quick as possible. In retrospect, we recognize this was not a good choice; title-level data are more meaningful. For example, the thirty-four-volume Dictionary of Art had thirty-eight uses over five years, but thirteen of the individual volumes had no dots affixed. In this example, then, 34 percent of the books received a zero in the spreadsheet, even though the title was clearly used. It is apparent that reporting multivolume title use is problematic, with the data often indicating a higher level of non-use than is warranted. Should this study be replicated, this is one aspect that needs to change.

We realized, too late, that the one student reshelver we had for two consecutive years was not following the established procedures for affixing the dots in the books. Because in her first year she did an excellent job, we have postulated that she was assuming that heavily used books already had ten dots and thus failed to dot them. Whatever the reason, there was a notable drop in use of key reference items, books that are required and consistently heavily used in the Bible College and Seminary courses. Indeed, the entire count for that year was 30 percent lower than that of the previous year, and 43 percent lower than that of the following year. Other reference statistics as well as observations of reference staff convince us that the data provided through the 


\section{FEATURE}

dots for that year are unreliable; they are accurate in what they do report, but inaccurate in what they do not.

\section{For Future Research}

Is aversion of librarians to weeding as pervasive as the literature seems to indicate? It is mentioned often, but more as an aside than as an empirically verified fact.

What is happening with reference book use statistics as electronic resources abound? If, as one might suspect, use is dropping, what are the implications? Generally, online databases do not contain the content found in the high-quality volumes that populate academic reference collections. If print reference use is decreasing, can it be assumed that our students, faculty, and even librarians are less scholarly in their quests for information? What are the weeding implications if use is dropping precipitously?

Would a follow-up study be correctly considered a follow-up study when electronic access to materials might significantly impact the use statistics of the print reference collection?

Is it verifiably, consistently true that more books in the lean reference collection will be used than in the fat (unweeded) collection?

\section{CONCLUSION}

The GAF reference staff thought that with collecting data at the end of the five-year study they would have finished the work. They now realize that the study has provided the information needed to begin several tasks. First, a mission statement and collection management policies will be developed. Library literature provides many articles that can be useful in guiding these tasks. ${ }^{27}$ It is, of course, understood that, once written, these documents are designed for guidance and not only can, but should, be reviewed regularly and revised as necessary. They are intended to aid librarians as we seek to meet patron needs, and should be utilized only insofar as they fulfill that intent.
After the mission and policies have been developed, a plan for weeding must be developed. Vincent's entertaining article provides excellent commentary regarding the extent to which reference weeding involves staff from throughout the library. ${ }^{28}$ Therefore, a plan that is developed in coordination with representatives from circulation and technical services is vital. Once the plan is in place, then both selection and deselection can happen within the parameters of the mission and policies.

If this researcher's review of the literature is accurate, CIU is not alone in having neither a mission nor policies to undergird the maintenance of the reference collection. Allow me, then, to leave the reader with the following challenges:

- In order to be proactive in maintaining our reference collections, academic reference librarians must define the intended use the reference collections in their institutions are to receive (mission) and the principles by which they will select and deselect items for those collections.

- Once these are in place, perhaps the more enthusiastic among us will begin a use study of their own. It is this researcher's fervent hope that having an automated ILS would make the more tedious aspects of this task far less odious. The CIU use study continues. Several librarians emphasized the helpfulness of the ready availability of use data throughout the fiveyear collection process. The CIU staff developed a different data collection method, but the end result will be the same. It would be interesting to compare CIU usage with that of other institutions that begin or continue their own reference collection use studies.

Bradford reports on a reference reshelving study using an ILS to record reshelving statistics. ${ }^{29}$ The procedure she describes seems nearly as tedious as that done at CIU. If academic reference librarians agree that reshelving studies are useful, perhaps a standard methodology can be developed so that our studies are true replications of each other.

Finally, we need to allow our policies to have an impact on how the reference collection is developed and maintained. The natural tendency is to complete the task of writing the policy and checking it off the to-do list, but not make any changes. This is perhaps the greatest challenge of all!

\section{ACKNOWLEDGEMENTS}

In addition to the CIU library staff, who endured more than colleagues should ever have to, I wish to acknowledge assistance from the following: Eugene Engeldinger, whose article inspired this research, graciously read and offered advice and encouragement. SHSU colleague Judy Ann Jerabek generously applied her excellent editorial skills as I revised the manuscript. Library school professor and friend Robert E. Molyneux listened, visited the site, read drafts, advised, and pestered me to finish.

\section{References}

1. Herman Howe Fussler and Julian Lincoln Simon, Patterns in the Use of Books in Large Research Libraries (Chicago: Univ. of Chicago Pr., 1969), 15.

2. Eugene A. Engeldinger, "Use' As a Criterion for the Weeding of Reference Collections: A Review and Case Study," The Reference Librarian no. 29 (1990): 119-28.

3. Robert N. Broadus, "Use Studies of Library Collections," Library Resources E Technical Services 24, no. 4 (1980): 317.

4. Ibid., 317-24.

5. Paul T. Adalian Jr. and Ilene F. Rockman, "Title-by-Title Review in Reference Collection Development," Reference Services Review 12 (Winter 1984): 85-88.

6. Ibid., 86.

7. Ibid., 87 .

8. Eugene A. Engeldinger, "Weeding of Academic Library Reference Collections: A Survey of Current Practice," RQ 25 (Spring 1986): 366-71.

9. Mary Biggs and Victor Biggs, "Reference Collection Development in Academic Libraries: Report of a Survey," RQ 27 (Fall 1987): 67-79.

10. Ibid., 69.

11. Daniel R. Arrigona and Eleanor Mathews, "A Use Study of an Academic Library 
Reference Collection," RQ 28 (Fall 1988): 71-81.

12. Carol Truett, "Weeding and Evaluating the Reference Collection: A Study of Policies and Practices in Academic and Public Libraries," The Reference Librarian no. 29 (1990): 53-67.

13. Ibid., 66 .

14. Engeldinger, "Use' As a Criterion," 11928.

15. Ibid., 126 .

16. Mary Biggs, "Discovering How Information Seekers Seek: Methods of Measuring Reference Collection Use," The Reference Librarian no. 29 (1990): 103-17.

17. Karen A. Sendi, "Assessing the Functionality of the Reference Collection," Collection Building 1, no. 3 (1996): 17-21.

18. Biggs and Biggs, "Reference Collection Development," 74-75.

19. Engeldinger, "'Use' As a Criterion," 12526.

20. Sendi, "Assessing the Functionality," 19.
21. Diane L. Fishman and Megan DelBaglivo, "Rich in Resources/Deficient in Dollars! Which Titles Do Reference Departments Really Need?" Bulletin of the Medical Library Association 86, no. 4 (1998): 548.

22. Engeldinger, "'Use' as a Criterion," 126.

23. Jesse H. Shera, "The Up-Side-Down Library," Utah Libraries 21 (Spring 1978): 15; Steven F. Vincent, "Let's Get Rid of It: A Reference Librarian's Battle Cry," The Reference Librarian no. 29 (1990): 151; Bart Harloe and Helen M. Barber, "Managing the Reference Collection: The Practice of Pruning," The Reference Librarian no. 29 (1990): 159-73; David Stoker, "Libraries at Bursting Point," Journal of Librarianship and Information Science 24 (June 1992): 160.

24. Christopher W. Nolan, "The Lean Reference Collection: Improving Functionality through Selection and Weeding," College E Research Libraries 52 (Jan. 1991): 86.
25. Ibid., 84 .

26. Truett, "Weeding and Evaluation," 59.

27. Kathleen Coleman and Pauline Dickinson, "Drafting a Reference Collection Policy," College \& Research Libraries 38 (May 1977): 227-33; Barbara Lehocky, Academic Reference Collection Development: Policy Statements (ERIC Reproduction Service, ED190160, 1979); Nolan, "The Lean Reference Collection," 80-91; David R. Majka, "Reference Collection Maintenance: Theory and (Mal)Practice," Reference Services Review 24, no. 4 (1996) 67-75; William A. Katz, Introduction to Reference Work, 7th ed., vol. 2 (New York: McGraw-Hill, 1997): 248-53.

28. Vincent, "Let's Get Rid of It," 145-57.

29. Jane T. Bradford "What's Coming Off the Shelves? A Reference use Study Analyzing Print Reference Sources Used in a University Library," Journal of Academic Librarianship 31, no. 6 (2005): 546-58. 